\title{
Translating Electronic Currents to Precise Acetylcholine-Induced Neuronal Signaling Using an Organic Electrophoretic Delivery Device
}

\author{
Klas Tybrandt, Karin C Larsson, Sindhulakshmi Kurup, Daniel Simon, \\ Peter Kjall, Joakim Isaksson, Mats Sandberg, Edwin Jager, \\ Agneta Richter-Dahlfors and Magnus Berggren
}

\section{Linköping University Post Print}

N.B.: When citing this work, cite the original article.

This is the authors' version of the final Publication:

Klas Tybrandt, Karin C Larsson, Sindhulakshmi Kurup, Daniel Simon, Peter Kjall, Joakim Isaksson, Mats Sandberg, Edwin Jager, Agneta Richter-Dahlfors and Magnus Berggren, Translating Electronic Currents to Precise Acetylcholine-Induced Neuronal Signaling Using an Organic Electrophoretic Delivery Device, 2009, Advanced Materials, (21), 44, 4442. http://dx.doi.org/10.1002/adma.200900187

Copyright: Wiley-VCH Verlag Berlin http://www.wiley-vch.de/publish/en/

Postprint available at: Linköping University Electronic Press http://urn.kb.se/resolve?urn=urn:nbn:se:liu:diva-52901 
DOI: 10.1002/adma.200900187

Translating electronic currents to precise acetylcholine-induced neuronal signaling using an organic electrophoretic delivery device**

By Klas Tybrandt, Karin C. Larsson, Sindhulakshmi Kurup, Daniel T. Simon, Peter Kjäll, Joakim Isaksson, Mats Sandberg, Edwin W. H. Jager, Agneta Richter-Dahlfors ${ }^{*}$ and Magnus Berggren*

[*] Prof. M. Berggren, K. Tybrandt, Dr. D.T. Simon, Dr. J. Isaksson, Dr. E.W.H Jager Organic Electronics, ITN, Linköping University

SE-601 74 Norrköping, Sweden

E-mail: magbe@itn.liu.se

Prof. A. Richter-Dahlfors, K.C. Larsson, Dr. S. Kurup, Dr. P. Kjäll

Department of Neuroscience, Karolinska Institutet

SE-171 77 Stockholm, Sweden

Agneta.Richter.Dahlfors@ki.se

Dr. M. Sandberg

Acreo AB, SE-602 21 Norrköping, Sweden

[**] K.T. and K.C.L contributed equally to this work. We thank the Swedish Foundation for Strategic Research (SSF) for funding of the project as part of the 'Bio-X program' (A.R.D. and M.B.) and the 'Strategic Research Centre for Organic BioElectronics' (OBOE) (M.B. and A.R.D.). The Organic Electronics group at Linköping University in Norrköping is a member of the COE@COIN project, also funded by the SSF. Funding from Karolinska Insitutet (the KID program) to K.C.L. is greatly appreciated.

Keywords: organic electronics, delivery, acetylcholine, spatiotemporal, neuronal signaling

Biological systems are regulated by complex communication networks characterized by transduction of bio-signals between cells. The resulting cellular activity is specified by the chemical and conformational nature of the signal ion / molecule as well as its spatiotemporal patterning. The importance of such spatiotemporal regulation is well documented, e.g. in $\mathrm{Ca}^{2+}$ signaling. ${ }^{[1,2]}$ However, further understanding is hampered due to inherent limitations of current delivery techniques for controlled stimulation of biological systems. To overcome these problems, engineers have developed complex micro- and nano-fluidic systems, often made from glass or plastics. ${ }^{[3,4]}$ These may include an assortment of valves and pumps for the regulation of substance delivery. ${ }^{[5-9]}$ Computer-controlled microfluidics for cell cultivation 
dynamics show promising results for and chemical signal generators for probing cellular dynamics show promising results for future investigation of cell signaling. ${ }^{[10,11]}$ However, microfluidic systems typically induce convection in the media, thereby altering the cellular microenvironment. In the worst case scenario, the liquid flow may cause detachment of surface-bound cells by mechanical forces. ${ }^{[12]}$ It may also disturb any inherent chemical gradient of signaling molecules secreted by cells for cell-to-cell communication. ${ }^{[13]}$ More subtle effects may also be introduced, as convection is known to cause shear stress that influences the biochemical behavior of cells, e.g. rearrangement of the cytoskeleton. ${ }^{[14]}$

Electronically controlled release systems can be a convection-free alternative to microfluidics. Silicon-based micro-reservoirs and -containers have been reported, in which the drug is released after electrochemical dissolution of a membrane. ${ }^{[15]}$ For more dynamically controlled release of biomolecules, conjugated polymers have been evaluated. The softness, flexibility, and ion permeability of organic materials make them suitable for interfacing biological systems. Drug delivery electrodes based on conjugated polymers have been reported, in which the release is triggered by an applied potential causing electrochemical reactions within the conjugated polymer, thus releasing the electrostatically bound dopant ions. ${ }^{[16-20]}$ Further, electronically controlled release from conducting-polymer nanotubes, fabricated on top of neuronal microelectrodes, have been demonstrated. ${ }^{[21]}$ Although these devices have many attractive properties, they typically operate in a time interval of minutes to hours and there have been no reports on spatiotemporal delivery with dynamics in the range of seconds.

We recently reported an Organic Electronic Ion Pump (OEIP), which takes advantage of the combined electronic and ionic conductivity of conjugated polymers to deliver metal cations to cells under convection-free conditions. ${ }^{[22,23]}$ OEIPs with 50 to $4000 \mu \mathrm{m}$ wide outlets were then utilized for delivery of $\mathrm{K}^{+}$to cells in concentrations above $50 \mathrm{mM}$. Because of residual ions in the channel, the delayed delivery time between addressing the pump and the induced cell responses was in the range of minutes. Here, we report on development of the OEIP 
Submitted to

\section{ADVANCED}

which has yielded i) expansion of the transport repertoire from metal cations to biomolecules, demonstrated by the neurotransmitter acetylcholine (ACh); $i$ ) miniaturized outlets down to 10 $\mu \mathrm{m}$ channels, i.e. equal to or smaller than the size of individual neuronal cells; and iii) a reduction of the delay time of delivery, from minutes to seconds, by incorporating a preloading circuit which also minimized undesired delivery of residual ions. The above achievements result in exact correlation between the addressing signal and the delivery rate of ACh, enabling stimulation of single SH-SY5Y neuroblastoma cells via local [Ach] in the range of $\mu \mathrm{M}$. Monitoring the induced $\mathrm{Ca}^{2+}$ responses we also demonstrate the electronic regulation of dynamic parameters, e.g. amplitude and frequency, and thereby the potential of this device to be used for further exploration of spatiotemporal patterning of cell signaling systems.

$\mathrm{ACh}$ is one of the major neurotransmitters in both the peripheral and central nervous systems where it effects e.g. synaptic plasticity and excitability. ${ }^{[24]}$ Its positive charge across the range of physiological $p H$ suggests that the chemistry of ACh would be compatible with the conducting polymer poly(3,4-ethylenedioxythiophene) doped with the polyanion poly(styrenesulfonate) (PEDOT:PSS) (Figure 1a). The principal device structure of the new $10 \mu \mathrm{m}$-OEIP consists of three electrochemically active PEDOT:PSS electrodes and an SU-8 encapsulation incorporating openings for source (S), target (T) and waste (W) electrolytes (Figures 1b, c). The S, T, and W electrodes were linked by a channel system with dimensions varying between 10,50 , and $200 \mu \mathrm{m}$. This balances optimal throughput with high spatial resolution. Overoxidation of PEDOT:PSS in these channels renders the PEDOT phase permanently electrically insulating while leaving the ionic conductivity of the PSS phase unaffected. ${ }^{[25]}$ Regions subjected to overoxidation serve as cationic exchange layers with substantially higher cationic than anionic conductivity. To achieve pumping of cations between two electrolytes the corresponding PEDOT:PSS electrodes are electrically addressed. The positively addressed electrode becomes oxidized while the negatively addressed electrode 
becomes reduced. ${ }^{[26,27]}$ This creates an electric field forcing cations to migrate through the channel (Figure 1d). Typically, the source reservoir contained $40 \mu \mathrm{l}$ of $0.1 \mathrm{M}$ acetylcholine chloride, the waste reservoir $40 \mu \mathrm{l} 0.1 \mathrm{M}$ sodium chloride $(\mathrm{NaCl})$, and the target reservoir contained cell medium, since this reservoir harbors the cells. Initially, the waste electrode was utilized for ACh loading of the channel by applying $V_{S W}=20 \mathrm{~V}$ for $3 \mathrm{~min}$ (SI 1). This scheme replaced the residual cations of the channel with $\mathrm{ACh}$, which provides highly improved accuracy when delivering small quantities, compared to the previously reported OEIP..$^{[22]}$ After disconnecting $V_{S W}$, a voltage was applied to $V_{S T}$ to initiate the migration of ACh from the source into the target electrolyte. The preloading procedure was shown to reduce the delivery delay time between addressing the $10 \mu \mathrm{m}$-OEIP to actual ACh delivery from minutes down to a few seconds.

To investigate the transport characteristics of ACh through the $10 \mu \mathrm{m}-\mathrm{OEIP}$, different addressing times and voltages were applied. Figure 2a displays the delivered amount of ACh (mean values and standard deviations) for $10 \mu \mathrm{m}$-OEIPs operated at $V_{S T}=20 \mathrm{~V}(n=3)$ and 40 $\mathrm{V}(n=3)$ together with representative electric currents vs. time. The electric current at $40 \mathrm{~V}$ is approximately twice as large as the current at $20 \mathrm{~V}$. Furthermore, the current is stable over long periods of time and the measured amount of ACh in the target electrolyte increases linearly with time. Linear fits reveal that the delivery rate of ACh is $0.26 \pm 0.02 \mathrm{pmol} \mathrm{s}^{-1}$ and $0.55 \pm 0.03 \mathrm{pmol} \mathrm{s}^{-1}$, for $20 \mathrm{~V}$ and $40 \mathrm{~V}$ respectively. The amount of ACh vs. the integrated current between the $\mathrm{S}$ and $\mathrm{T}$ electrodes, i.e. the transported charge, is given in Figure $\mathbf{2 b}$. The linear slope gives a nearly constant transporting efficiency of $103 \pm 3 \%\left(\Sigma n_{\mathrm{ACh}} / \Sigma n_{\text {charge }}\right)$ within a range of different addressing times and voltages. As each charge corresponds to one ACh molecule, the above results demonstrate the feasibility of using a conjugated polymer device to facilitate precision delivery of one of the most important signaling molecules in the nervous system, the neurotransmitter ACh. 


\section{Submitted to

Another important feature for delivery devices is the ratio between the delivery rate and spontaneous leakage, i.e. on-off ratio. In the PEDOT:PSS-based OEIP, active delivery is driven by migration while leakage is governed by diffusion. Recently, we reported an OEIP on-off ratio above 300 for alkali cations. ${ }^{[22]}$ Here, leakage of ACh from the channel outlet into the target reservoir was found to be below the detection level of the measurement method used. However, assuming the Nernst-Planck equation applies, the drift vs. diffusion currents of ACh equals $J_{\text {deliver }} / J_{\text {leak }}=(F / R T) \cdot V_{S T} \approx 40 V_{S T}$. Thus, for $V_{S T}=10 \mathrm{~V}$ the expected on-off ratio is 400 . The on-off ratio can further be improved by applying a negative voltage between the waste and target electrodes in the off state.

The potential of the $10 \mu \mathrm{m}$-OEIP for spatiotemporal delivery of ACh in cell signaling experiments was next explored in in vitro studies. In the nervous system, signaling agents such as ions $\left(\right.$ e.g. $\left.\mathrm{Ca}^{2+}, \mathrm{K}^{+}\right)$and neurotransmitters are utilized to relay, amplify, and modulate signals. The human SH-SY5Y neuroblastoma cell line possess subtypes of the cholinergic ACh receptors, and has been widely used in a variety of $\mathrm{Ca}^{2+}$ signaling experiments for studies of voltage-dependent $\mathrm{Ca}^{2+}$ entry and receptor-mediated $\mathrm{Ca}^{2+}$ homeostasis. ${ }^{[28,29]}$ For a general overview of ACh-receptor induced $\mathrm{Ca}^{2+}$ responses, readers are referred to reference $\# 30^{[30]}$. Microscopy-based real-time single-cell $\mathrm{Ca}^{2+}$ imaging of SH-SY5Y cells represents an ideal read-out system to monitor the cellular response to ACh. To enable accurate single cell stimulation in vitro, knowledge of local concentrations at a given time is crucial. We therefore modeled the evolution of the ACh concentration generated when biasing $V_{S T}=5 \mathrm{~V}$ from $t=0$ $100 \mathrm{~s}$ (Figure 2c, SI 2). This corresponds to an associated delivery rate of approximately 0.07 pmol s${ }^{-1}$. Hypothetically, a cell located $50 \mu \mathrm{m}$ away from the outlet would be exposed to 140 $\mu \mathrm{M}$ ACh after $5 \mathrm{~s}$, whereas at $150 \mu \mathrm{m}$ the concentration would be $0.3 \mu \mathrm{M}$.

To test this hypothesis, we used SH-SY5Y cells as bio-sensors, since cholinergic AChreceptor stimulation, using $10 \mu \mathrm{M} \mathrm{ACh}$, is known to induce $\mathrm{Ca}^{2+}$ influx. ${ }^{[31]}$ Cells cultivated on the target electrode were loaded with the ratiometric $\mathrm{Ca}^{2+}$ fluorophore Fura 2-AM (Figure 1c 


\section{ADVANCED}

and 2d). After pre-loading the $10 \mu \mathrm{m}$-OEIP microchannel with $\mathrm{ACh}$, baselines of intracellular $\mathrm{Ca}^{2+}$ levels were recorded. The low-intensity fluorescence, reflected by the steady baseline, reveals that the surface per se does not induce any $\mathrm{Ca}^{2+}$ response. By applying $V_{S T}=5 \mathrm{~V}$, an increase in intracellular $\mathrm{Ca}^{2+}$ was rapidly observed in cells located within a radius of $50 \mu \mathrm{m}$ from the channel outlet (Figure 3a). To characterize the evolving [ACh] at different distances from the channel outlet, we measured the time to half-maximal fluorescence intensity $\left(T_{\max 1 / 2}\right)$ in cells. $T_{\max 1 / 2}$ in cells located $>150 \mu \mathrm{m}$ from the outlet showed delayed $\mathrm{Ca}^{2+}$ response with average $T_{\max 1 / 2}=20 \mathrm{~s}$ compared to $T_{\max 1 / 2}=11 \mathrm{~s}$ for cells $<50 \mu \mathrm{m}$ from the outlet $(\mathrm{n}=3)$ (Figure 3a). This result validates the theoretically calculated [ACh] generated at various distances from the channel outlet (compare Figures 2c and 3a). Control experiments were performed with $\mathrm{NaCl}$ as source electrolyte to analyse whether activation of the pump triggers $\mathrm{Ca}^{2+}$ response. When $\mathrm{Na}^{+}$, an ion that does not signal via the $\mathrm{Ca}^{2+}$ pathway, was transported at $\mathrm{V}_{\mathrm{ST}}=20 \mathrm{~V}$, neither the electric field nor the potential induced any intracellular $\mathrm{Ca}^{2+}$ response (Figure 3b). However, SH-SY5Y cells responded promptly when ACh was added manually, using a pipette, into the target electrolyte $(n=3)$ (Figure 3b). The latter experiment demonstrates that the negative result of $\mathrm{Na}^{+}$transport is not a consequence of unhealthy cells. This series of experiments demonstrates that $i$ ) ACh can be transported through the PEDOT:PSS polymer; ii) transport through the polymer does not affect ACh's biological activity; and iii) electronic addressing of the $10 \mu \mathrm{m}-\mathrm{OEIP}$ provides temporal control of delivered ACh molecules.

Dynamic parameters of biological signals, such as speed, amplitude, and spatiotemporal patterning, can be used to regulate diverse cellular processes. ${ }^{[32]} \mathrm{We}$ investigated whether the electronically controlled $10 \mu \mathrm{m}$-OEIP can modulate dynamic parameters, such as amplitude and speed, of cellular $\mathrm{Ca}^{2+}$ signals. By applying $V_{S T}=1 \mathrm{~V}$ for $60 \mathrm{~s}$, transported ACh elicited an intracellular $\mathrm{Ca}^{2+}$ response, which declined when $V_{S T}$ was turned off (Figure 3c). When intracellular $\mathrm{Ca}^{2+}$ had returned to a lower fluorescence level, a second pulse of $V_{S T}=10 \mathrm{~V}$ was 
applied for $60 \mathrm{~s}$. This time, the $\mathrm{Ca}^{2+}$ response reached a substantially higher amplitude because of the 10 -fold increase in applied $V_{S T}(\mathrm{n}=5)$. Furthermore, varying the rate of ACh delivery, using 1 and $10 \mathrm{~V}$, the dynamics of the $\mathrm{Ca}^{2+}$ transients can be electronically modulated, as indicated by the slopes. Figure $3 \mathrm{c}$ shows representative single-cell $\mathrm{Ca}^{2+}$ tracing, whereas the fluorescent read-out represented by an imaging sequence can be found in Supplementary Information (SI 3).

The device was then tested for its suitability to generate regular, oscillating $\mathrm{Ca}^{2+}$ signals in single cells exposed to temporally controlled release of ACh. By applying a high voltage $\left(V_{S T}\right.$ $=20 \mathrm{~V})$ for a short time $(<1 \mathrm{~s})$, we hypothesized that a local increase of ACh would be generated that transiently activates individual cells. When ACh transport is interrupted, the high local $[\mathrm{ACh}]$ is expected to instantly collapse due to rapid diffusion of the neurotransmitter into the cell medium (SI 4). A typical response of SH-SY5Y cells exposed to an ACh pulse-train is presented in Figure 3d. The first pulse of delivered ACh $\left(V_{S T}=20 \mathrm{~V}\right.$ for $0.2 \mathrm{~s})$ rapidly induced a $\mathrm{Ca}^{2+}$ transient in cells located within $50 \mu \mathrm{m}$ from the channel outlet, whereas cells located $>150 \mu \mathrm{m}$ away were unresponsive $(n=3)$. Thus, the spatial resolution of single cell stimulation is improved 5-fold compared to that previously reported. ${ }^{[22]}$ Once intracellular $\mathrm{Ca}^{2+}$ had decreased to a lower fluorescence plateau, cells were exposed to the next ACh pulse, again resulting in a cellular $\mathrm{Ca}^{2+}$ transient. By repeating the procedure, a pulse train was generated with a temporal pattern mimicking that of naturally occurring $\mathrm{Ca}^{2+}$ oscillations (Figure 3d). This experiment also illustrates that the amplitude of the $\mathrm{Ca}^{2+}$ transient can be modulated by extending the time of applied pulses $(0.2,0.4,0.6,0.8,1.0$ and $2.0 \mathrm{~s})$. In contrast to the shorter pulses, the longest pulse $(2.0 \mathrm{~s})$ resulted in a sufficiently high [ACh] to induce $\mathrm{Ca}^{2+}$ response also in the cell located > $150 \mu \mathrm{m}$ away from the outlet.

The $10 \mu \mathrm{m}$-OEIP presented here fulfills several important, previously unachievable requirements for cell signaling research. With this device, spatial resolution of individual cell stimulation in the range of $50-100 \mu \mathrm{m}$ is achieved. Whereas the ionic conductivity of 
conducting polymers in the OEIP previously has been utilized for transport of small (1-40 Da) cations $\left(\mathrm{H}^{+}, \mathrm{Na}^{+}, \mathrm{K}^{+}, \mathrm{Ca}^{2+}\right)$, here we demonstrate the feasibility of this material for precise lateral transport of a positively charged, $146 \mathrm{Da}$ biomolecule, the neurotransmitter ACh. The pre-loading circuit combined with the $10 \mu \mathrm{m}$-channel allows for fine-tuning of substance delivery, i.e. concentrations in the $\mu \mathrm{M}$ range can be precisely achieved. Parameterization of this all-solid state $10 \mu \mathrm{m}$-OEIP device reveals excellent correlation between the electronic addressing signal, i.e. the current and voltage, and the associated delivery rate. We

demonstrate the usability of these features for dynamic operation of the $10 \mu \mathrm{m}$-OEIP, providing a means of controlling parameters involved in the spatiotemporal patterning of intracellular $\mathrm{Ca}^{2+}$ responses. Moreover, the $10 \mu \mathrm{m}$-OEIP can be processed using standard photolithography and printing techniques that are easily integrated with other organic or inorganic solid-state systems. Taken together, this promises for further development of allsolid-state systems to create an interface where complex high-resolution signal patterns are generated to control cell physiology at the single cell and even sub-cellular level.

\section{Experimental}

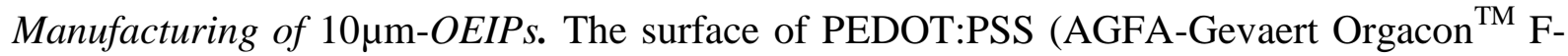
350 ), coated on a polyethylene terephthalate substrate, was cleaned using $1112 \mathrm{~A}$ remover (Shipley), then rinsed in acetone and deionized water. Shipley 1805 photoresist was deposited onto the PEDOT:PSS surface after pre-treatment with $\mathrm{O}_{2}$-plasma and primer (hexamethyldisilazane). PEDOT:PSS was patterned using a $\mathrm{O}_{2} / \mathrm{CF}_{4}$ plasma etch-step. Overoxidized patterns of PEDOT:PSS were achieved by exposing the unsealed PEDOT:PSS areas to a sodium hypochlorite solution (1\% (vol/vol), 20 s). Finally, a top layer of SU-8 2010 (MicroChem) was patterned on top of the electrode configuration and the target electrode was exposed to $\mathrm{O}_{2}$ plasma etch through a plastic mask. 


\section{Submitted to

Measurement of ACh Transport. Devices were soaked in deionized water for $24 \mathrm{~h}$ prior to use. $\mathrm{V}_{\mathrm{ST}}$ was applied with a Keithley 2602 source meter controlled via LabVIEW. The S electrolyte consisted of $\mathrm{AChCl}(40 \mu \mathrm{l}, 0.1 \mathrm{M}$, Sigma $\geq 99 \% \mathrm{TLC})$ and $\mathrm{NaCl}(40 \mu 1,0.1 \mathrm{M})$ was used as T electrolyte. For each device, samples from $\mathrm{T}$ were collected after 100, 600, 1600, 3600, and $6600 \mathrm{~s}$. The $\mathrm{T}$ electrode was repeatedly cleaned five times with a $\mathrm{NaCl}$ before a fresh electrolyte was applied. Collected samples were analyzed with an Amplex ${ }^{\circledR}$ Red Acetylcholine/Acetylcholinesterase Assay Kit (Molecular Probes).

Cell Cultivation. Human neuroblastoma SH-SY5Y cells (ATCC nr: CRL-2266) were propagated according to instructions from the supplier, in a 1:1 mixture of Eagle's Minimum Essential Medium (Sigma) and F12 medium (Sigma) supplemented to final concentrations of $10 \%$ fetal bovine serum (Sigma), L-glutamine ( $2 \mathrm{mM}$, Invitrogen), $1 \%$ non-essential amino acids (Sigma), penicillin (100 U ml-1, Sigma), streptomycin (0.1 mg ml-1, Sigma) and 1\% Hepes (Sigma). Cells were propagated in $6 \mathrm{ml}$ cell culture medium in tissue culture flasks $\left(25-\mathrm{cm}^{2}\right.$, Sarstedt), which were maintained in a humidified, $37{ }^{\circ} \mathrm{C}, 5 \% \mathrm{CO}_{2}$ incubator, with the medium exchanged twice a week. At $80 \%$ confluency, cells were re-seeded at a ratio of 1:5. The night before the experiment, $10^{5}$ cells (passage 6-20) were seeded on the target electrode in fresh medium. Water (Fischer Scientific, cell culture grade) was simultaneously placed on the remaining electrodes to hydrate the polymer over night.

Intracellular $\mathrm{Ca}^{2+}$ Recordings. To prepare cells for $\mathrm{Ca}^{2+}$ recordings, cells were incubated with the membrane-permeable $\mathrm{Ca}^{2+}$-sensitive dye FURA-2 AM ( $2 \mu \mathrm{M}$, Molecular Probes $)$ and $0.02 \%$ pluronic acid (Molecular Probes) in a humidified incubator $\left(37^{\circ} \mathrm{C}\right)$. After $1 \mathrm{~h}$, Fura-2 AM was replaced with fresh cell media $(50 \mu \mathrm{l})$. The $10 \mu \mathrm{m}$-OEIP was prepared by applying ACh $(50 \mu 10.1 \mathrm{M}$, Fluka) as source electrolyte and $\mathrm{NaCl}(50 \mu \mathrm{l} 0.1 \mathrm{M}$, Sigma) as waste electrolyte. Pre-loading of the transport channel was performed by applying $V_{S W}=20 \mathrm{~V}$ for 3 
min. The basal level of intracellular $\mathrm{Ca}^{2+}$ was recorded before the ion pump was activated using potentials as described. Cells located at $<50 \mu \mathrm{m}$ and $>150 \mu \mathrm{m}$ away from the channel outlet were monitored using a Nikon TS-100 inverted microscope equipped with a $40 \times / 0.75$ epifluorescence objective or an upright Nikon Eclipse 80i with a 40 x /0.80 epifluorescence objective. Excitation at 340 and $380 \mathrm{~nm}$ was achieved with a DeltaRAM illuminator and a DeltaRAM-V monochromator with a computer controlled SC500 shutter controller. Emission $(510 \mathrm{~nm})$ was collected every 4 or $8 \mathrm{~s}$ with a Photometrics Coolsnap CCD camera. Data were analyzed using PTI ImageMaster3 Software. $T_{\max 1 / 2}$ was calculated by subtracting the time at which the half maximum fluorescence intensity was reached after voltage application from the time at which the voltage was applied. Each set of experiments was repeated a minimum of three times, representative recordings are presented.

Received: ((will be filled in by the editorial staff))

Revised: ((will be filled in by the editorial staff)) Published online: ((will be filled in by the editorial staff))

\section{References}

[1] K. Mikoshiba, J. Neurochem. 2007, 102, 1426-1446.

[2] M. J. Berridge, M. D. Bootman, H. L. Roderick, Nat. Rev. Mol. Cell Biol. 2003, 4, $517-529$

[3] J. de Jong, R. G. H. Lammertink, M. Wessling, Lab Chip 2006, 6, 1125-1139.

[4] J. M. K. Ng, I. Gitlin, A. D. Stroock, G. M. Whitesides, Electrophoresis 2002, 23, $3461-3473$.

[5] A. Brask, D. Snakenborg, J. P. Kutter, H. Bruus, Lab Chip 2006, 6, 280-288.

[6] J. Noo Li, D. T. Chiu, C. J. Wargo, W. Hongkai, I. S. Choi, J. R. Anderson, G. M. Whitesides, Biomed. Microdevices 2002, 4, 117-121.

[7] H. Suzuki, R. Yoneyama, Sens Actuators B Chem 2003, B96, 38-45. 
[8] H. Xu, C. Wang, C. Wang, J. Zoval, M. Madou, Biosens Bioelectron 2006, 21, 20942099.

[9] P. F. Pettersson, E. W. H. Jager, O. Inganas, presented at 1st Annual International IEEE-EMBS Special Topic Conference on Microtechnologies in Medicine \& Biology, Lyon, France, Oct 12-14, 2000.

[10] W. Gu, X. Y. Zhu, N. Futai, B. S. Cho, S. Takayama, Proc. Natl. Acad. Sci. U. S. A. 2004, 101, 15861-15866.

[11] B. Kuczenski, W. C. Ruder, W.C. Messner, P.R. Leduc, PLoS ONE 2009, 4(3), e4847.

[12] X. L. Zhang, H. B. Yin, J. M. Cooper, S. J. Haswell, Electrophoresis 2006, 27, 5093.

[13] V. V. Abhyankar, M. A. Lokuta, A. Huttenlocher, D. J. Beebe, Lab Chip 2006, 6, 389.

[14] C. S. Chen, J. Tan, J. Tien, Annu. Rev. Biomed. Eng. 2004, 6, 275.

[15] Y. Li, R. S. Shawgo, B. Tyler, P. T. Henderson, J. S. Vogel, A. Rosenberg, P. B. Storm, R. Langer, H. Brem, M. J. Cima, J. Controlled Release 2004, 100, 211-219.

[16] L. L. Miller, React. Polym., Ion Exch., Sorbents 1986, 6, 341.

[17] K. Kontturi, P. Pentti, G. Sundholm, J. Electroanal. Chem. 1998, 453, 231-238.

[18] P. M. George, D. A. Lavan, J. A. Burdick, C.-Y. Chen, E. Liang, R. Langer, Adv. Mater. 2006, 18, 577-581.

[19] M. Pyo, J. R. Reynolds, Chem. Mater. 1996, 8, 128-133.

[20] R. Wadhwa, C. F. Lagenaur, X. T. Cui, J. Controlled Release 2006, 110, 531-541.

[21] M. R. Abidian, D.-H. Kim, D. C. Martin, Adv. Mater. 2006, 18, 405-409.

[22] J. Isaksson, P. Kjäll, D. Nilsson, N. Robinson, M. Berggren, A. Richter-Dahlfors, Nat. Mater. 2007, 6, 673-679.

[23] J. Isaksson, P. Kjäll, D. Nilsson, N. D. Robinson, M. Berggren, A. Richter-Dahlfors, Org. Electron. 2008, 9, 303-309.

[24] G. J. Augustine, D. Fitzpatrick, W. C. Hall, A.-S. LaMantia, J. O. McNamara, R. D. Mooney, M. L. Platt, D. Purves, S. A. Simon, L. E. White, S. M. Williams, in Neuroscience, 
Fourth Edition, (Eds: D. Purves, G. J. Augustine, D. Fitzpatrick, W. C. Hall, A.-S. LaMantia, J. O. McNamara, L. E. White), Sinauer Associates InC, Sunderland Massachusetts 2008, 90.

[25] P. Tehrani, N. D. Robinson, T. Kugler, T. Remonen, L.-O. Hennerdal, J. Hall, A. Malmstrom, L. Leenders, M. Berggren, Smart Mater. Struct. 2005, 14, 21-25.

[26] L. Groenendaal, F. Jonas, D. Freitag, H. Pielartzik, J. R. Reynolds, Adv. Mater. 2000, $12,481-494$.

[27] Q. Pei, G. Zuccarello, M. Ahlskog, O. Inganäs, Polymer 1994, 35, 1347-1351.

[28] R. J. Lukas, S. A. Norman, L. Lucero, Mol. Cell. Neurosci. 1993, 4, 1-12.

[29] D. G. Lambert, E. M. Whitham, J. G. Baird, S. R. Nahorski, Mol. Brain Res. 1990, 8, 263-266.

[30] F. Dajas-Bailador, S. Wonnacott, Trends Pharmacol. Sci. 2004, 25, 317.

[31] S. Fucile, M. Napolitano, E. Mattei, Biochem. Biophys. Res. Commun. 1997, 230, 501.

[32] M. J. Berridge, P. Lipp, M. D. Bootman, Nat. Rev. Mol. Cell Biol. 2000, 1, 11-21. 
a)

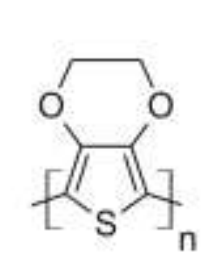<smiles>[123I]</smiles><smiles></smiles>

PEDOT PSS

ACh

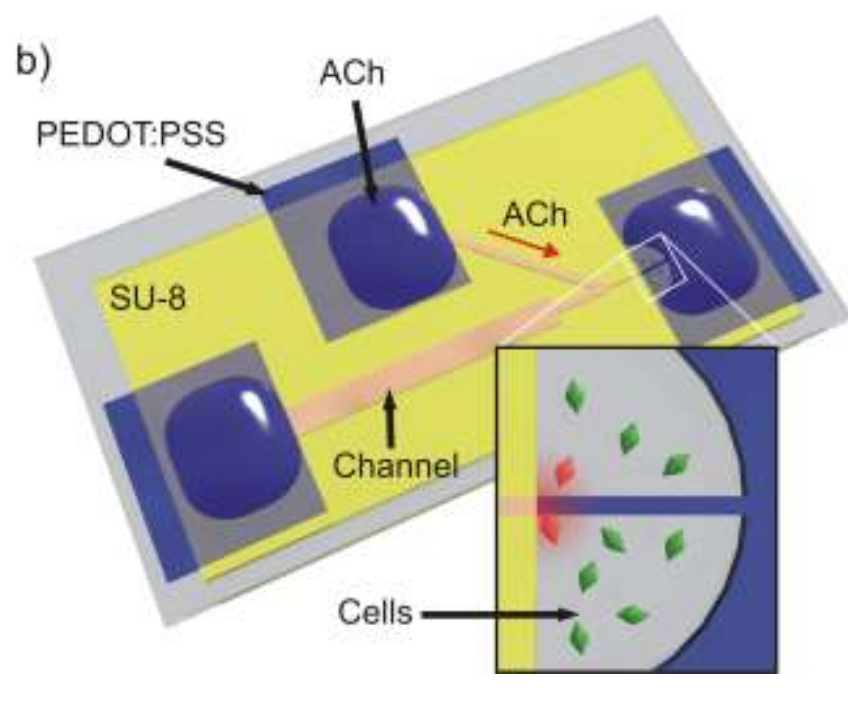

b)

c)

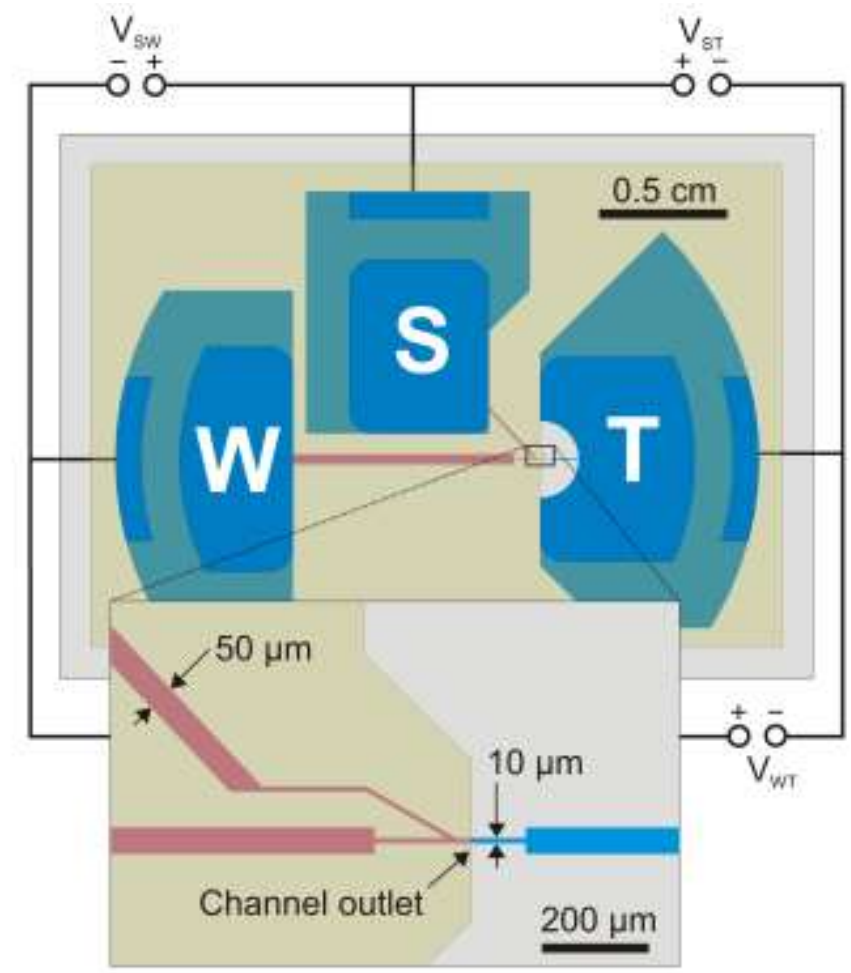

d)

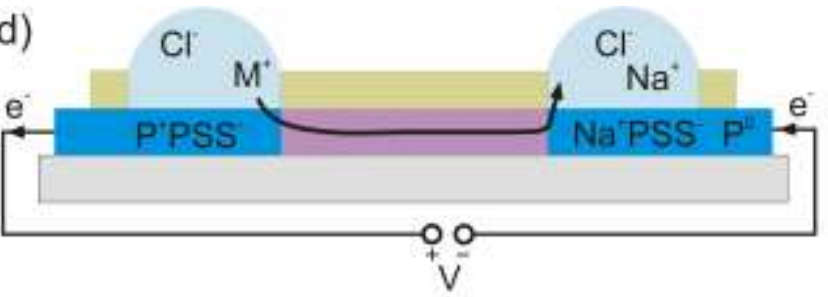

Figure 1 The Organic Electronic Ion Pump. (a) Molecular structures of the conductive polymer PEDOT:PSS and the neurotransmitter ACh. (b) Overview of the 10um-OEIP. The electrically conducting PEDOT:PSS electrodes are connected by cation selective polyelectrolyte channels. The SU-8 layer serves as insulation and encapsulation layer with defined openings for the electrolytes. ACh is transported through the channel and released

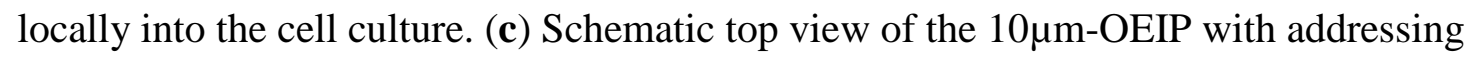
voltages. Electrodes are labeled source (S), target (T) and waste (W) according to their use. The zoomed area shows the $10 \mu \mathrm{m}$ wide channel entering the target electrolyte at the SU-8 border. (d) Schematic cross section along the channel connecting two electrodes. The applied potential between the electrodes creates a closed electrochemical circuit, in which the electric current is compensated by an ionic current of the same magnitude through the channel. Thus the mobile cations $\mathrm{M}^{+}$in the target electrolyte are transported through the channel and immediately released into the source electrolyte due to the thinness of the channel ( $\sim 200 \mathrm{~nm})$. In this process, the source electrode is oxidized and the target electrode is reduced. 


\section{Submitted to \\ ADNANCEP
MAATRRALS}

a)

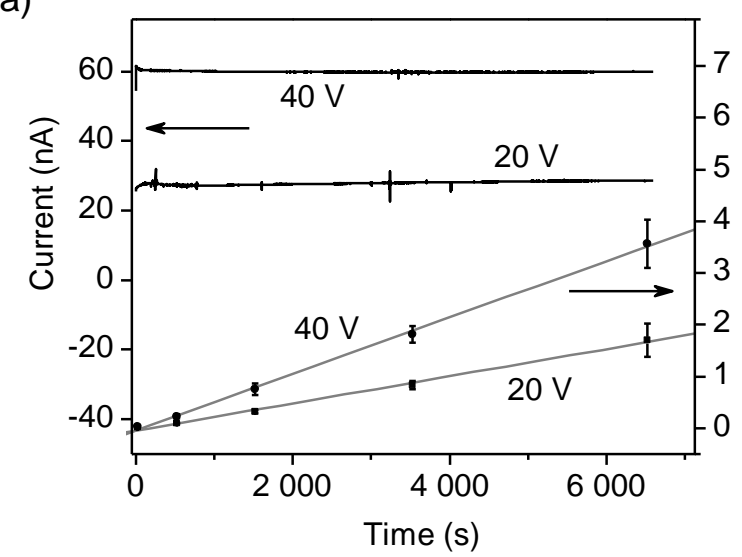

c)

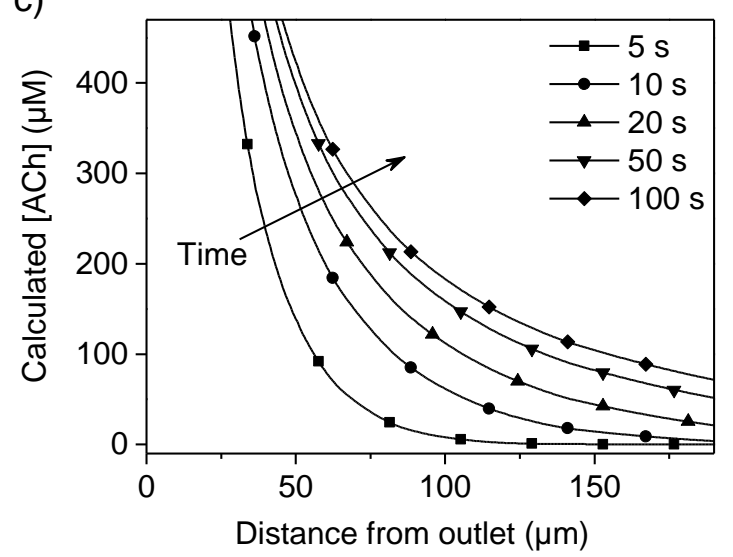

b)

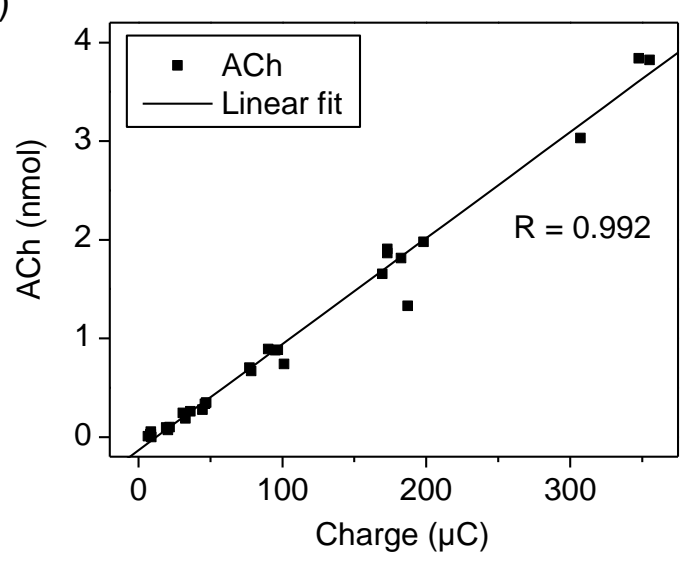

d)

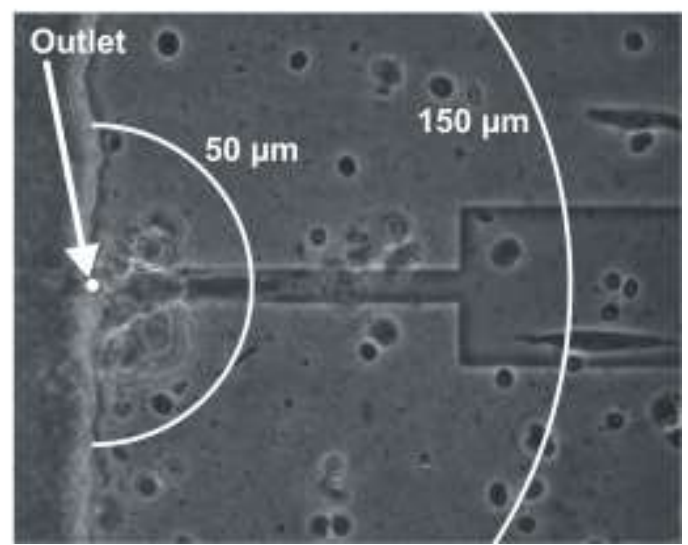

Figure $2 \mathrm{ACh}$ transport in $10 \mu \mathrm{m}$-OEIPs. (a) Characterization with $V_{S T}$ set to $20 \mathrm{~V}$ and $40 \mathrm{~V}$.

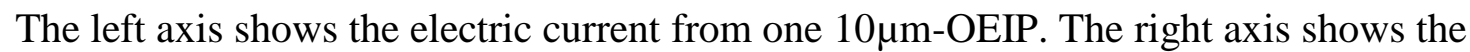
transported amount of ACh in the target electrolyte. Samples were collected from three $10 \mu \mathrm{m}-$ OEIPs at each voltage and the mean values, standard deviations and linear fits are shown. (b) Relationship between transported amount of ACh and integrated electric current. (c) Calculated evolution of [ACh] from the $10 \mu \mathrm{m}$-OEIP outlet with $V_{S T}$ set to $5 \mathrm{~V}$ at time zero. (d) Light microscope image of SH-SY5Y cells at various distances (50 and $150 \mu \mathrm{m}$ ) from the $10 \mu \mathrm{m}$ channel outlet on the $10 \mu \mathrm{m}-\mathrm{OEIP}$. 


\section{Submitted to

a)

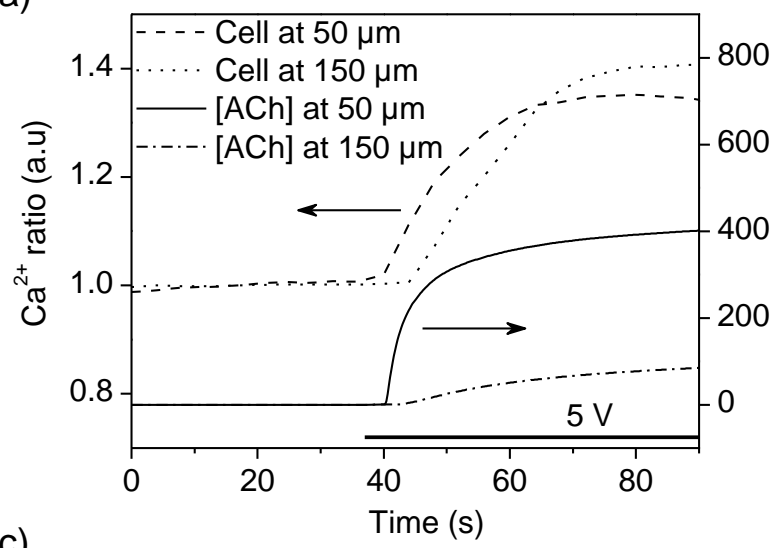

c)

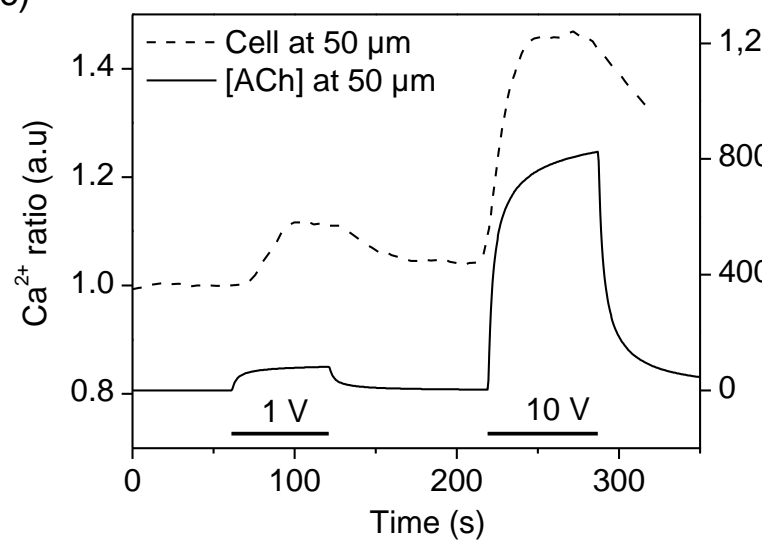

b)

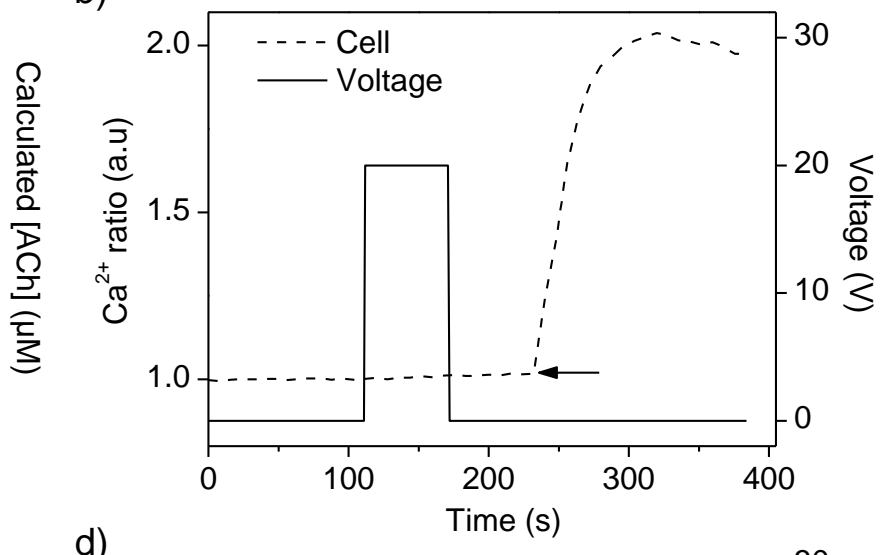

d)

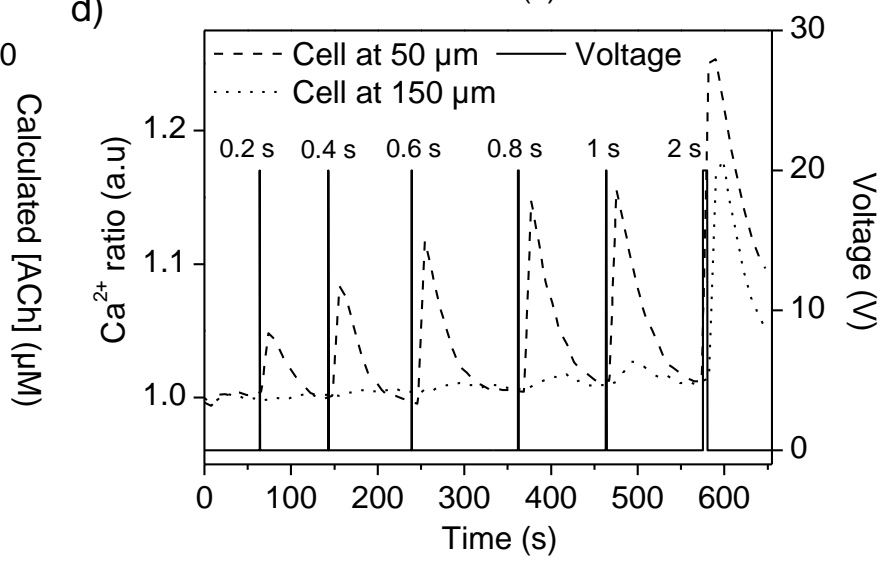

Figure 3 Intracellular $\mathrm{Ca}^{2+}$ recordings of SH-SY5Y cells. (a) Transport of ACh from source $(0.1 \mathrm{M} \mathrm{ACh})$ to target at $V_{S T}=5 \mathrm{~V}$. Cells located $<50 \mu \mathrm{m}$ from the outlet respond immediately by an increase in fluorescence while a $9 \mathrm{~s}$ delayed response is observed in cells located $>150$ $\mu \mathrm{m}$ from the outlet. (b) Transport of $\mathrm{Na}^{+}$from source $(0.1 \mathrm{M} \mathrm{NaCl})$ to target at $V_{S T}=20 \mathrm{~V}$. The arrow indicates manual addition of $\mathrm{ACh}$ to a final concentration of $1 \mathrm{mM}$ in the target electrolyte. (c) The rate and amplitude of the $\mathrm{Ca}^{2+}$ responses can be modulated by applying 1 and $10 \mathrm{~V}$ for $60 \mathrm{~s}$. (d) Applying a pulse-train of $V_{S T}=20 \mathrm{~V}$ for $0.2,0.4,0.6,0.8,1.0$ and $2.0 \mathrm{~s}$ generates intracellular $\mathrm{Ca}^{2+}$ oscillations. The increasing pulse lengths are reflected in increased amplitude of the $\mathrm{Ca}^{2+}$ response. Short pulses result in high local [ACh] that induces local stimulation of single cells $<50 \mu \mathrm{m}$ while cells $>150 \mu \mathrm{m}$ from the outlet are nonresponsive. 


\section{Submitted to \\ ADANCEPS
MATERRALIS}

\section{The table of contents entry :}

A miniaturized organic electronic ion pump (OEIP) based on conjugated polymers is developed for delivery of positively charged bio-molecules. Characterization shows that applied voltage can precisely modulate the delivery rate of the neurotransmitter acetylcholine. The capability of the device is demonstrated by convection-free, spatiotemporally resolved delivery of acetylcholine via a $10 \mu \mathrm{m}$ channel for dynamic stimulation of single neuronal cells.

Keyword (see list)

organic electronics, delivery, acetylcholine, spatiotemporal, neuronal signaling

Klas Tybrandt, Karin C. Larsson, Sindhulakshmi Kurup, Daniel T. Simon, Peter Kjäll, Joakim Isaksson, Mats Sandberg, Edwin W. H. Jager, Agneta Richter-Dahlfors ${ }^{*}$, Magnus Berggren ${ }^{*}$

Title ((no stars))

Translating electronic currents to precise acetylcholine-induced neuronal signaling using an organic electrophoretic delivery device

ToC figure ((55 $\mathrm{mm}$ broad, $50 \mathrm{~mm}$ high, or $110 \mathrm{~mm}$ broad, $20 \mathrm{~mm}$ high $)$ )

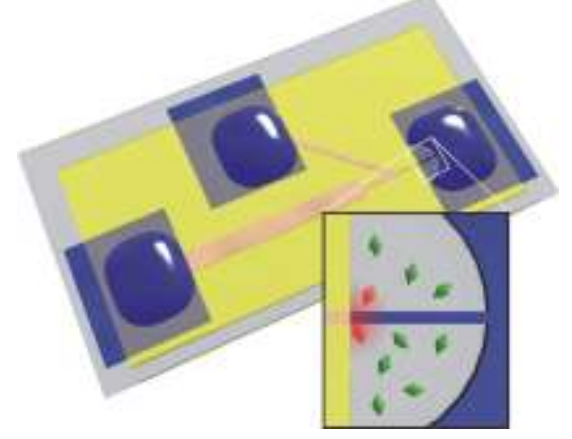

